\title{
Global weak solution to a generic reaction-diffusion nonlinear parabolic system
}

\author{
Matallah Hana ${ }^{1}$, MESSAOUD MAOUNI ${ }^{1}$, and Hakim Lekhal ${ }^{1}$ \\ ${ }^{1}$ Laboratory of Applied Mathematics and History and Didactics of Mathematiccs \\ (LAMAHIS), University of 20 August 1955, skikda, Algeria
}

March 3, 2021

\begin{abstract}
We consider a new generic reaction-diffusion system, given as the following form: [?] $\mathrm{u} /[?] \mathrm{t}-\operatorname{div}\left(\mathrm{g}\left(-\left([?] \mathrm{u} \_\sigma\right)-\right)[?] \mathrm{u}\right)=\mathrm{f}(\mathrm{t}, \mathrm{x}, \mathrm{u}, \mathrm{v},[?] \mathrm{v})$, in Q_T [?] $/[?] \mathrm{t}-\mathrm{d}_{-} \mathrm{v} \Delta \mathrm{v}=\mathrm{p}(\mathrm{t}, \mathrm{x}, \mathrm{u}, \mathrm{v},[?] \mathrm{u})$, in $\mathrm{Q}_{-} \mathrm{T} \mathrm{u}(0,)=.\mathrm{u}_{-} 0, \mathrm{v}(0,)=.\mathrm{v}_{-} 0$, in $\Omega(1)[?] \mathrm{u} /[?] \eta=0,[?] \mathrm{v} /[?] \eta=0$, in [?]_T. Where $\Omega=] 0,1[? \times] 0,1\left[, \mathrm{Q}_{-} \mathrm{T}=\right] 0, \mathrm{~T}[?$ and $\mathrm{T}=] 0, \mathrm{~T}\left[?,(\mathrm{~T}>0), \eta\right.$ is an outward normal to domain $\Omega$ and $\mathrm{u}_{-} 0$, v_0 is the image to be processed, $\mathrm{x}[?] \Omega, \sigma>0,[?] \mathrm{u}_{-} \sigma=\mathrm{u}^{*}[?] \mathrm{G}_{-} \sigma$ and $\mathrm{G}_{-} \sigma=1 /[?] 2 \pi \sigma \exp \left(-\mathrm{x}_{-}{ }^{\wedge} 2 / 4 \sigma\right)$. In this study we are going to proof that there is a global weak solution to the ptoblem (1), we truncate the system and show that it can be solved by using Schauder fixed point theorem in Banach spaces. Finally by making some estimations, we prove that the solution of the truncated system converge to the solution of the problem.
\end{abstract}

\section{Hosted file}

Global weak solution to a generic reaction-diffusion nonlinear parabolic system.pdf available at https://authorea.com/users/399209/articles/511770-global-weak-solution-to-ageneric-reaction-diffusion-nonlinear-parabolic-system 